\title{
Meat export competitiveness of European Union countries on global markets
}

\author{
Štefan Bojnec ${ }^{1}$ and Imre Fertö2,3 \\ ${ }^{1}$ University of Primorska, Faculty of Management, Cankarjeva 5, SI-6104 Koper, Slovenia \\ ${ }^{2}$ Corvinus University, Fővám tér 8, H-1093 Budapest, Hungary \\ ${ }^{3}$ Institute of Economics, Hungarian Academy of Sciences, Budaörsi u. 45, H-1112 Budapest, Hungary \\ e-mail: stefan.bojnec@fm-kp.si
}

\begin{abstract}
The purpose of this research is to provide insight into the export competitiveness of meat products of the European Union (EU-27) member states on global markets. The revealed comparative advantage index is used to analyze the levels, compositions, and evolutions in patterns of development in the export competitiveness of meat products and their levels of stability at the product level. Except for some niche meat products, a larger number of the EU-27 member states have experienced comparative disadvantages on global markets over the analysed years of 2000 to 2011. The revealed comparative advantages on the global markets are the most robust for Ireland, Spain, the Netherlands, France, Belgium, Denmark, Poland, Cyprus and Hungary. The revealed comparative advantage indices and their survival rates differ across the meat product groups. The heterogeneity in export competitiveness of the EU-27 member states suggests the importance of the differentiation of meat products in competitive export specialization on global markets.
\end{abstract}

Key words: Meat value chain, global trade, revealed comparative advantage, survival analysis, mobility indices

\section{Introduction}

The global meat industry is in a stage of major structural changes, with advances in breeding and genetics, slaughtering and the development of new processing automation technology (modernization and rationalization in the way meat is harvested, processed and packed) and the increasing role of the distribution of a variety of fresh and processed products on the global meat market (Van der Zijpp 1999, Zhou et al. 2012, Barbut 2014). These new challenges and opportunities on the global meat market, with the increasing role of automation, computer control systems and global marketing towards greater product uniformity and quality, are particularly focused on the issues of global export competitiveness, which are of increasing business and policy concerns.

Thus far, there has not been a study to analyse export competitiveness on the global meat markets, and particularly not for the EU-27 member states, which has motivated this research, which aims to highlight export competitiveness using the revealed comparative advantage (RCA) index on the global markets. More specifically, this paper investigates the export competitiveness of the European Union (EU-27) member states in meat products at the different levels of the meat supply chain in the 2000-2011 period. The sample of the EU-27 member states was selected because of the importance of their livestock farming systems in working towards sustainability in livestock farming and the global trade in meat products (Boyazoglu 1998, Gibon et al. 1999, Bojnec and Peter 2005, FAO 2013). The success (or lack thereof) of the meat value chain on global markets is a crucial factor for the economic sustainability of the meat sector (Nardone et al. 2010). The development of differentiated meat value chains can be a significant factor in achieving sustainable competitiveness towards changing consumer needs and demands.

On the basis of the empirical evidence, implications of the importance of the management of the commercial meat export supply chain and policy implications for the meat chain are derived. Export specialization in differentiated meat products of the EU-27 member states implies the importance of food processing innovation-diversification activities for segmented consumer perceptions on global meat markets. The export competitive strategies of the EU-27 member states are based on diversification of the meat product chain with associated meat supply chain quality assurance and marketing approaches. These supply chain management approaches are typical for monopolistic competition to be competitive with diversified product quality and product varieties. This is crucial for supply chain management of the meat product from farms to consumers, with the relations between farms and inter-firm quality management systems and inter-firm governance structures for the efficient coordination of the quality of end-customer products in meat supply chains (Hansson et al. 2010, Wever et al. 2010). 
The analysis of this paper is also significant for the entire meat supply in that it provides better understanding of the complexities of interactions in differentiated meat product supply chains. The improved information system and the new knowledge gained can contribute to better understanding of meat product export competitiveness as essential for decision-making processes in order to improve performance on global markets.

\section{Materials and methods}

\section{Data}

An empirical analysis of the RCA indices for meat chain products on the global market is conducted for the EU-27 member states, using detailed trade data of the six-digit World Customs Organization's Harmonized System (HS6) level for the years from 2000 to 2011 . The United Nations International Trade Statistics UN Comtrade database (UNSD 2013) at the World Customs Organization's the International Standard Industrial Classification (ISIC Revision 2 ) is used for meat exports of the EU-27 member states to the global markets. Meat chain product trade defined by the International Standard Industrial Classification (ISIC-3112) contains 86 HS-6 code meat product groups. To obtain more information on the meat chain products, the concordance between the HS- 6 code and Broad Economic Categories (BEC) systems was used to transform data from the HS-6 code to the BEC including four main categories: BEC 21 - primary meat products (17 HS-6 code items); BEC 22 - industrial meat supplies not elsewhere specified; processed (6 HS-6 code items); BEC 121 - processed meat mainly for industry (1 HS-6 code item); and BEC 122 - processed meat mainly for household consumption (62 HS-6 code items).

The UN Comtrade database with the World Integrated Trade Solution (WITS) software is used in the RCA calculations.

\section{Revealed comparative advantage index}

Different alternative trade intensity and trade specialization measures have been developed in literature to assess trade advantage and trade competitiveness (e.g. Bojnec and Fertő 2012a). Lafay (1992) explains two significant differences between comparative trade advantage and trade competitiveness. First, competitiveness usually involves a cross-country comparison for a particular product, whilst comparative advantage is measured between products within a country. Second, competitiveness is subject to changes in macroeconomic variables, whereas comparative advantage is structural in nature. Finally, comparative advantage and competitiveness measures share all the interdependencies and dynamic aspects of an economy, and both measures may also be affected by policy distortions ${ }^{1}$.

Following a body of literature on the methodological approach of the RCA index, which is widely used in empirical trade literature to identify a country's weak and strong export sectors (Balassa 1965, Bojnec and Fertő 2012a, 2012b), the RCA index is defined as follows:

$\mathrm{RCA}=(\mathrm{Xij} / \mathrm{Xim}) /(\mathrm{Xwj} / \mathrm{Xwm})$

where $X$ represents exports, $i$ is an EU-27 member state, $j$ is a meat product, $m$ is a set of commodities, and $w$ is a set of countries in the world, which is used as the benchmark of comparison. The RCA index is based on observed export patterns. It measures a country's exports of a meat product relative to the country's total merchandise exports and to the corresponding export performance of a set of countries, e.g. the global meat exports relative to its total merchandise exports. If RCA $>1$, then a country's meat product comparative advantage on the global market is revealed, i.e. a meat product group in which the country is relatively more specialized in terms of exports. In this case, Xij describes individual EU-27 member states' $i$ meat product exports, respectively, for a particular meat product group $j$ to the global markets, whilst Xim is total merchandise exports of individual EU-27 member states $i$ respectively, to global markets. Xwj denotes the global exports for a given meat product $j$ and Xwm the total global merchandise exports, which are used as the benchmark of comparison.

Despite some criticism, the use of the RCA index as export specialization/competitiveness measure remains popular in the empirical trade literature for the following reasons. First, other variants of trade indices are less theoretically based than the RCA index (Hillman 1980, Hinloopen and van Marrewijk 2008). Second, forced symmetry

${ }^{1}$ The term 'comparative advantage' is, in the pure meaning of the related trade theory, connected to an interpretation based on relative factor endowments, which are implicitly represented by each county, but not explicitly modelled, in this paper. 
in the symmetric revealed comparative advantage (SRCA) index, which was developed by Dalum et al. (1998), and in the normalized revealed comparative advantage (NRCA) is problematic from the interpretation (and econometric) perspective (De Benedectis and Tamberi 2004). Third, from the binary demarcation perspective, for a product with and without revealed comparative advantage the numerical examples for the NRCA index vis-à-vis alternative trade indices indicate that the results are identical to the RCA index in terms of identification of comparative advantage/disadvantage (Yu et al. 2009).

In this paper, the RCA index is classified into two categories: RCA $<1$ refers to all those meat product groups with an absence of revealed comparative advantage or to meat products with a revealed comparative disadvantage. RCA $>1$ refers to all those meat product groups with a revealed comparative advantage. These boundaries are consistent with the theoretical interpretation appropriate for cross-country comparisons between RCA $<1$ and RCA $>1$.

\section{Stability tests}

The stability of the value of the RCA indices on the global market for particular meat product groups is investigated in two complementary steps. First, the Markov chain model is a common way of estimating intra-distribution dynamics and the structural stability of the trade specialization indices over time. The methods of evaluating intra-distribution dynamics was originally proposed by Quah $(1993,1997)$ for the analysis of cross-country income convergence. Later, it was used in empirical studies on countries' trade specialization dynamics (e.g. Brasili et al. 2000, Redding 2002, Zaghini 2005, Alessandrini et al. 2007, Fertő and Soós 2008). Meat chain products are classified into two categories: meat chain products with a revealed comparative disadvantage $(R C A<1)$ and meat chain products with a revealed comparative advantage (RCA $>1$ ). The transition probabilities for the RCA index can be estimated by counting the number of transitions out of and into each cell. The interpretation of persistence or mobility throughout the entire distribution of the RCA index can be easily studied by using a transition probability matrix. The high values of the Markov transition probability matrix along the diagonal suggest high persistence, whilst high values for off-diagonal elements imply high mobility.

Second, the degree of mobility in patterns of revealed comparative advantage can be summarized by using an index of mobility; this formally evaluates the degree of mobility throughout the entire distribution of RCA indices and facilitates direct cross-country comparisons. The mobility index, $M_{1}$, following Shorrocks (1978), evaluates the trace ( $\mathrm{tr}$ ) of the Markov transition probability matrix. This $M_{1}$ index thus directly captures the relative magnitude of diagonal and off-diagonal terms, and can be shown to equal the inverse of the harmonic mean of the expected duration of remaining in a given class:

$$
\mathrm{M}_{1}=\frac{\mathrm{K}-\operatorname{tr}(\mathrm{P})}{\mathrm{K}-1}
$$

where $\mathrm{K}$ is the number of classes, and $\mathrm{P}$ is the Markov transition probability matrix. A higher value of the $\mathrm{M}_{1}$ index indicates greater mobility (the upper limit is two in this case), with a value of zero indicating perfect immobility.

The next step to examine is the duration of revealed comparative advantage. Calculating the duration then appears to be straightforward: it is simply the time (measured in years) that a product has maintained comparative advantage without any interruption. Alternatively, applying statistical techniques from survival analysis, the duration can be modelled as a sequence of conditional probabilities that a product's revealed comparative advantage $(R C A>1)$ continues after $t$ periods, given that it has already survived for $t$ periods. Specifically, let $T$ be a random variable that denotes the length of a spell. Then, in discrete time, the survival function, $S(T)$, is defined as:

$$
S(T)=\operatorname{Pr}(T \geq t) \text {. }
$$

In empirical studies, the survival functions are estimated (in a non-parametric way) by computing the number of spells that survive (end) as a fraction of the total number of spells that are at risk after $t$ periods. More specifically, the duration of the revealed comparative advantage (RCA $>1$ ) for each of the EU-27 countries is estimated applying the nonparametric Kaplan-Meier product limit estimator (Cleves et al. 2004).

The Kaplan-Meier estimator of the hazard function is the fraction of spells that fail after $t$ periods of all spells that have survived $t$ periods. The survivor function is the share of spells that survives at time $t$, but this time is cumulative of all preceding time intervals. That is, if all spells survive and the ratio is one, the survivor function is flat at this interval; otherwise, the function is stepwise declining. 
Formally, the Kaplan-Meier estimator of the survival function is:

$$
\hat{S}(t)=\prod_{t(i)<t} \frac{n_{j}-d_{j}}{n_{j}}
$$

where $n_{j}$ denotes the number of subjects at risk of failing at $t\left({ }_{j}\right)$, and $d_{j}$ denotes the number of observed failures. Given that many observations are censored, it is then noted that the Kaplan-Meier estimator is resistant to censoring and uses information from both censored and non-censored observations. It is possible that in some cases the revealed comparative advantages $(R C A>1)$ were dissolved $(R C A<1)$ and later re-established $(R C A>1)$ during the sample period. The episodes of uninterrupted revealed comparative advantage $(R C A>1)$ are the primary unit of analysis.

\section{Results \\ RCA indices}

Figure 1 presents the RCA indices on the global market for meat products for each of the EU-27 member states in 2000 and $2011^{2}$. The results of the EU-27 member states are mixed. Some states have had revealed comparative advantages $(R C A>1)$ in meat products: Belgium, Bulgaria, Cyprus, Denmark, France, Hungary, Ireland, Lithuania, the Netherlands, Poland, and Spain.

In contrast, there is a larger group of the EU-27 member states with a revealed comparative disadvantage $(\mathrm{RCA}<1)$ on the global meat markets: Estonia, Finland, Germany, Greece, Luxembourg, Malta, Portugal, Romania, Slovenia, Sweden, and Slovakia.

Improvements from RCA $<1$ to RCA $>1$ are seen for Austria, Italy, and the United Kingdom (UK). The deterioration from RCA $>1$ to $R C A<1$ is seen for the Czech Republic and Latvia. These mixed results support the main finding that most of the EU-27 member states are not competitive or their export competitiveness in meat products on the global markets has deteriorated, e.g. for Latvia, Lithuania, Hungary, Cyprus and most other new EU member states. ${ }^{3}$

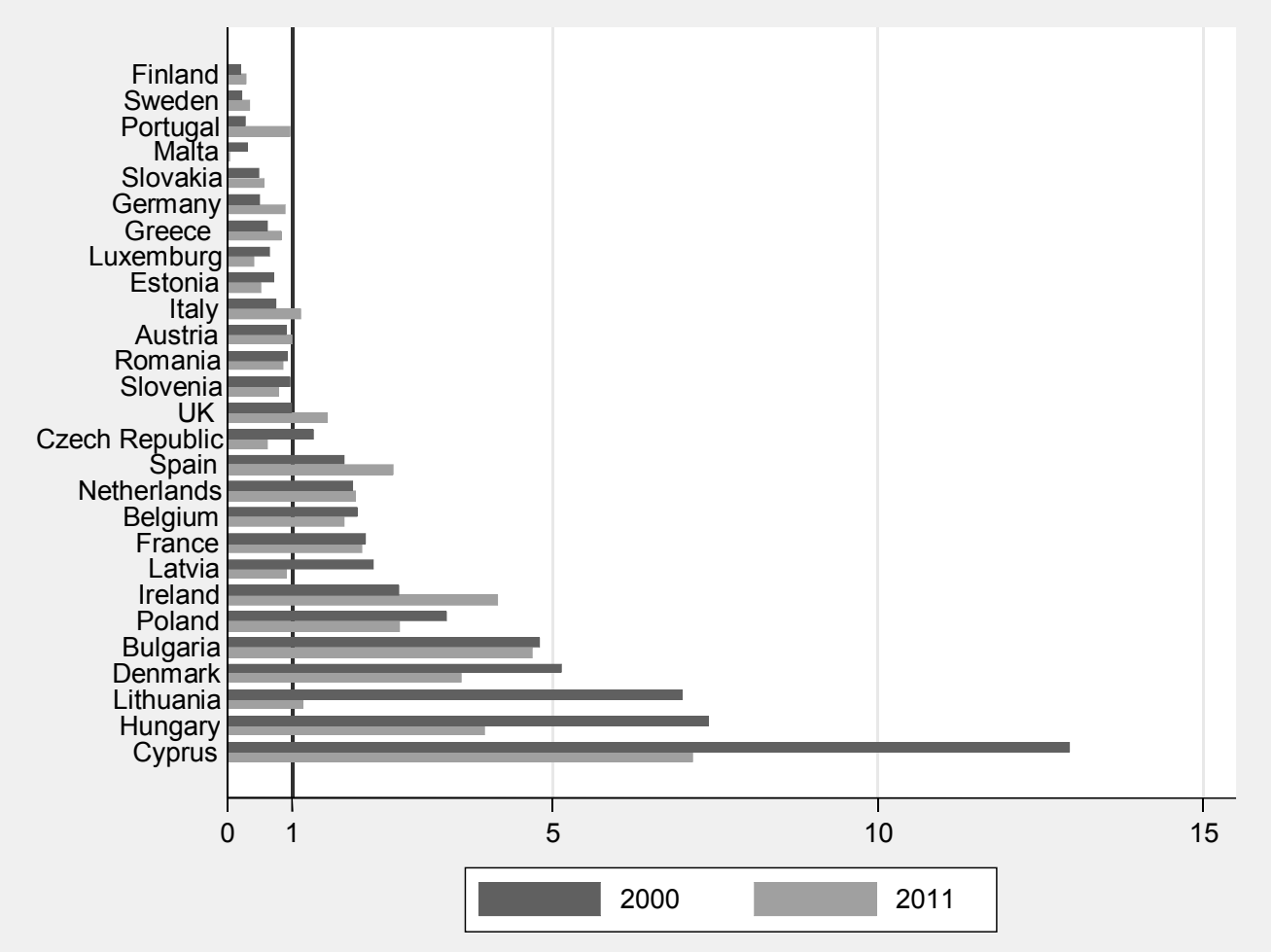

Fig. 1. Revealed comparative advantage (RCA) indices on the global market for meat products by the EU-27 member states, 2000 and 2011. Source: Own calculations based on Comtrade database with WITS (World Trade Integration Solution) software.

${ }^{2}$ The levels of the RCA indices for meat products by the BEC meat group of products for each of the EU-27 countries over the analyzed years (2000-2011) are available from the authors upon request.

${ }^{3}$ The new EU-12 member states are: Cyprus, the Czech Republic, Estonia, Hungary, Latvia, Lithuania, Malta, Poland, Slovakia, and Slovenia from the enlargements on 1st May 2004, and Bulgaria and Romania from the enlargements on 1st January 2007. Other analyzed EU-15 member states are considered to be old member states. 


\section{RCA indices by the BEC meat product groups}

Almost half of the EU-27 member states have experienced revealed comparative advantages (RCA $>1)$ on the global markets in the BEC 21 - primary meat products: Austria, Belgium, Bulgaria, Cyprus, Denmark, Greece, Hungary, Ireland, the Netherlands, Spain, the UK, as well as Portugal, Slovakia and Slovenia (Fig. 2).

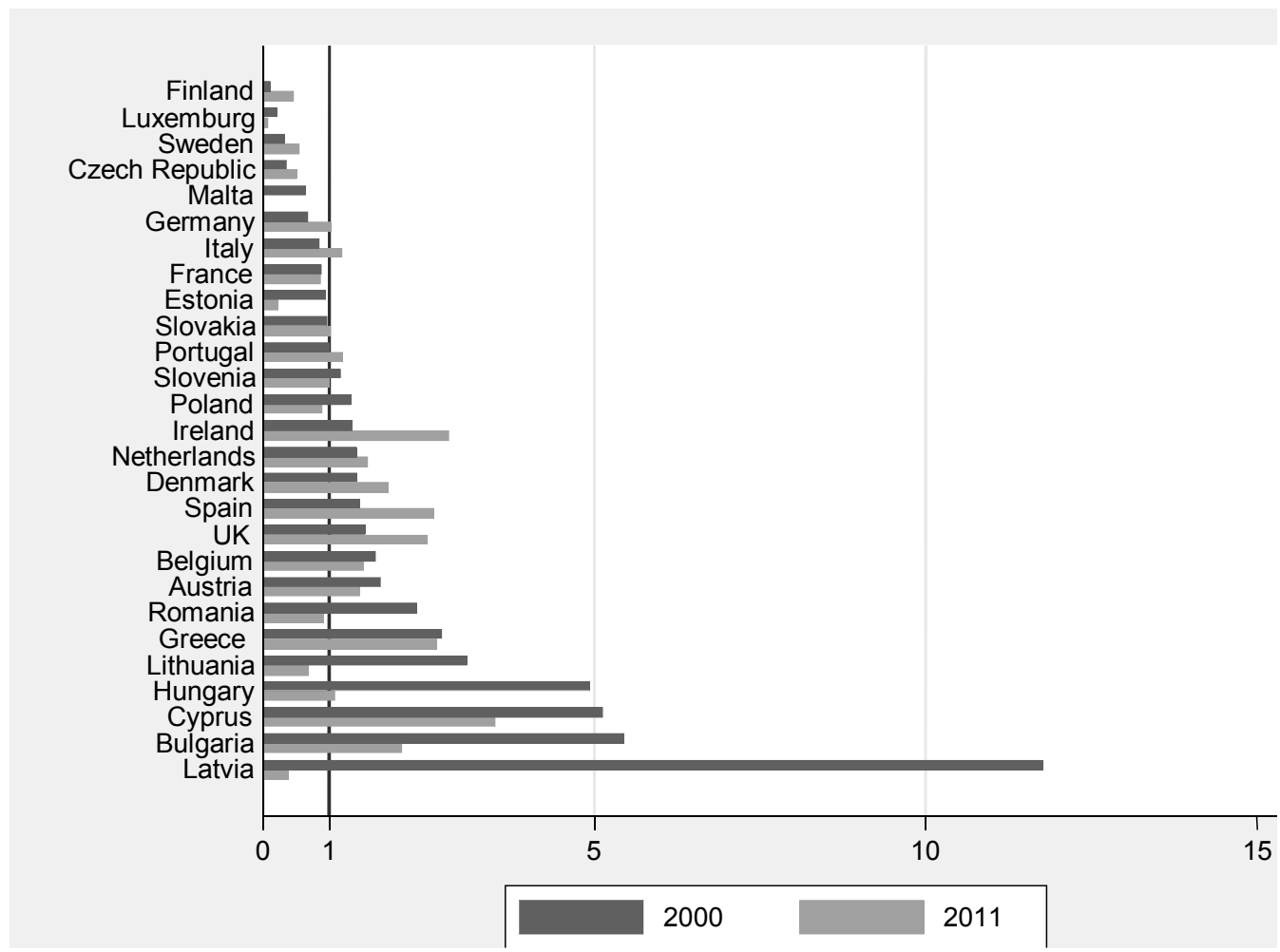

Fig. 2. Revealed comparative advantage (RCA) indices on the global market for the BEC 21 - primary meat products by the EU-27 member states, 2000 and 2011. Source: Own calculations based on Comtrade database with WITS (World Trade Integration Solution) software.

Seven of the EU-27 member states have experienced revealed comparative disadvantages $(\mathrm{RCA}<1)$ on the global markets in the BEC 21: the Czech Republic, Finland, France, Luxembourg, Sweden, Estonia and Malta. With the EU accessions in 2004 and 2007, a deterioration in export competitiveness from RCA $>1$ to RCA $<1$ on the global market is seen for Latvia, Lithuania, Poland and Romania. The deterioration in export competitiveness for BEC 21 is also seen for other new EU member states, e.g. Bulgaria, Cyprus, Estonia, Hungary and Slovenia. The improvements in export competitiveness are seen for most of the old EU member states, e.g. for Germany, Italy, Portugal, Ireland, the Netherlands, Denmark, Spain, and the UK.

Only a small number of the EU-27 member states have experienced revealed comparative advantages (RCA $>1)$ on the global markets for the BEC 22 - industrial meat supplies: Belgium, Denmark, France, Slovakia, the UK, Ireland, and Spain (Fig. 3).

A larger group of the EU-27 member states have experienced revealed comparative disadvantages $(R C A<1)$ on the global markets for the BEC 22: Austria, Bulgaria, the Czech Republic, Estonia, Finland, Germany, Greece, Latvia, Lithuania, Malta, Portugal, Slovenia, and Sweden. 


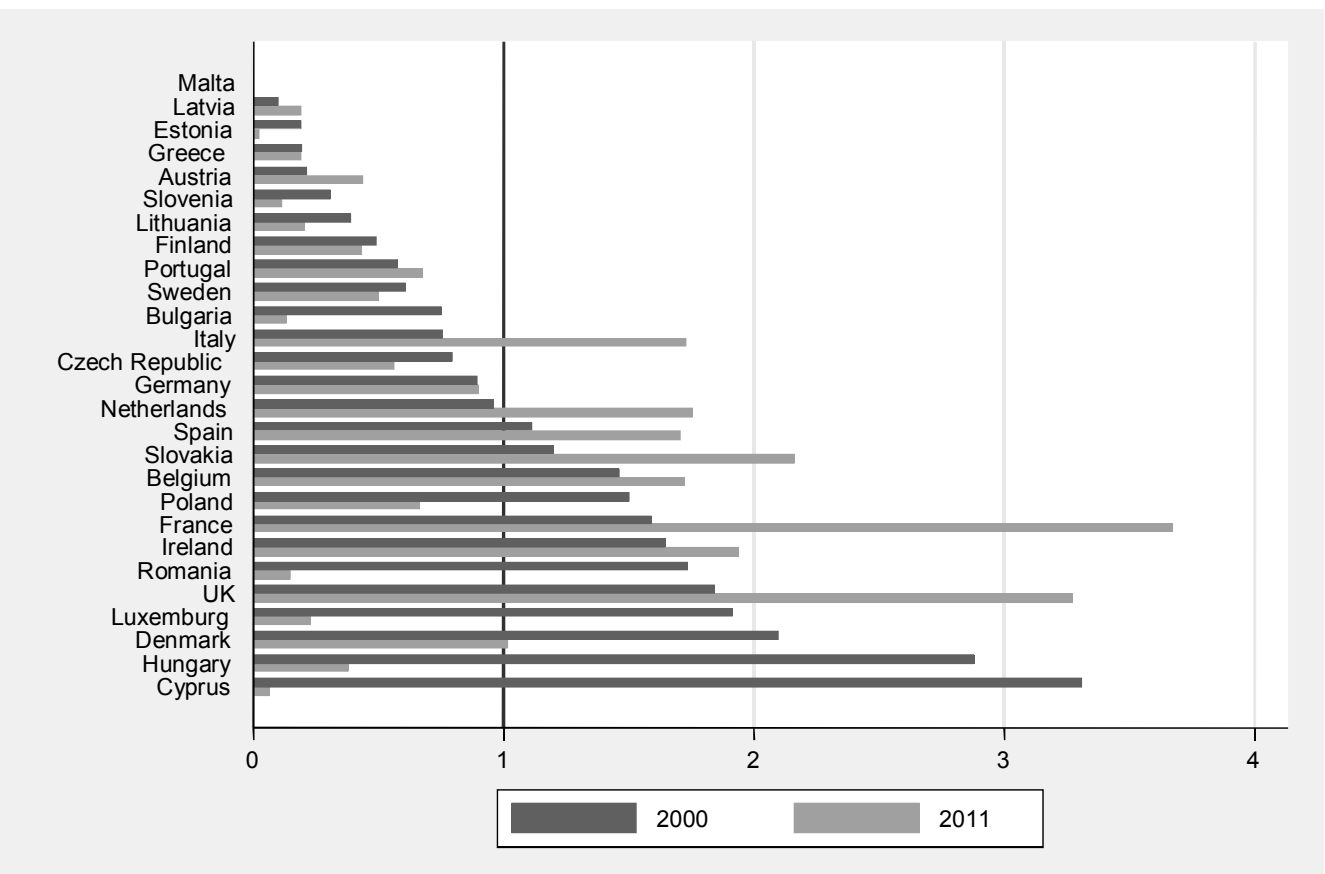

Fig. 3. Revealed comparative advantage (RCA) indices on the global market for the BEC 22 -industrial meat supplies not elsewhere specified; processed by the EU-27 member states, 2000 and 2011. Source: Own calculations based on Comtrade database with WITS (World Trade Integration Solution) software.

A deterioration of export competitiveness with a shift from $\mathrm{RCA}>1$ to $\mathrm{RCA}<1$ on the global market can be seen for Cyprus, Hungary, Luxembourg, Poland, and Romania; this worsening in export competitiveness for most of the new EU member states can be explained by a lack of export competitiveness in the meat-processing industry. An improvement in export competitiveness with a shift from $\mathrm{RCA}<1$ to $\mathrm{RCA}>1$ can be seen for Italy and the Netherlands.

The RCA indices for the BEC 121 - processed meat products mainly for industry are mixed between the EU-27 member states (Fig. 4). The first main group of the nine EU-27 member states has a revealed comparative advantage $(R C A>1)$ on the global markets: Belgium, Denmark, France, Hungary, Ireland, Italy, the Netherlands, Poland, and Spain.

The second group of the thirteen EU-27 member states has a revealed comparative disadvantage $(\mathrm{RCA}<1)$ on the global markets: Bulgaria, the Czech Republic, Finland, Greece, Latvia, Luxembourg, Malta, Portugal, Romania, Slovakia, Slovenia, Sweden, and the UK.

An improvement of export competitiveness with a shift from $\mathrm{RCA}<1$ to $\mathrm{RCA}>1$ can be seen for Austria, Cyprus, Germany, and Lithuania. A deterioration in export competitiveness with a shift from $R C A>1$ to $R C A<1$ can be seen for Estonia.

Eleven of the EU-27 member states have experienced a revealed comparative advantage (RCA>1) on the global markets for the BEC 122 - processed meat and meat products intended for final consumption in households: Belgium, Bulgaria, Cyprus, Denmark, France, Hungary, Ireland, Lithuania, the Netherlands, Poland, and Spain (Fig. 5).

In contrast, eleven of the EU-27 member states have experienced a revealed comparative disadvantage $(\mathrm{RCA}<1)$ on the global markets for the BEC 122: Austria, Estonia, Finland, Germany, Greece, Luxembourg, Malta, Portugal, Romania, Slovakia, and Sweden.

A shift with export competitiveness improvements from RCA $<1$ to RCA $>1$ can be seen for Italy, Latvia, and the UK. A deterioration in export competitiveness with a shift from RCA $>1$ to $R C A<1$ can be seen for the Czech Republic and Slovenia. 


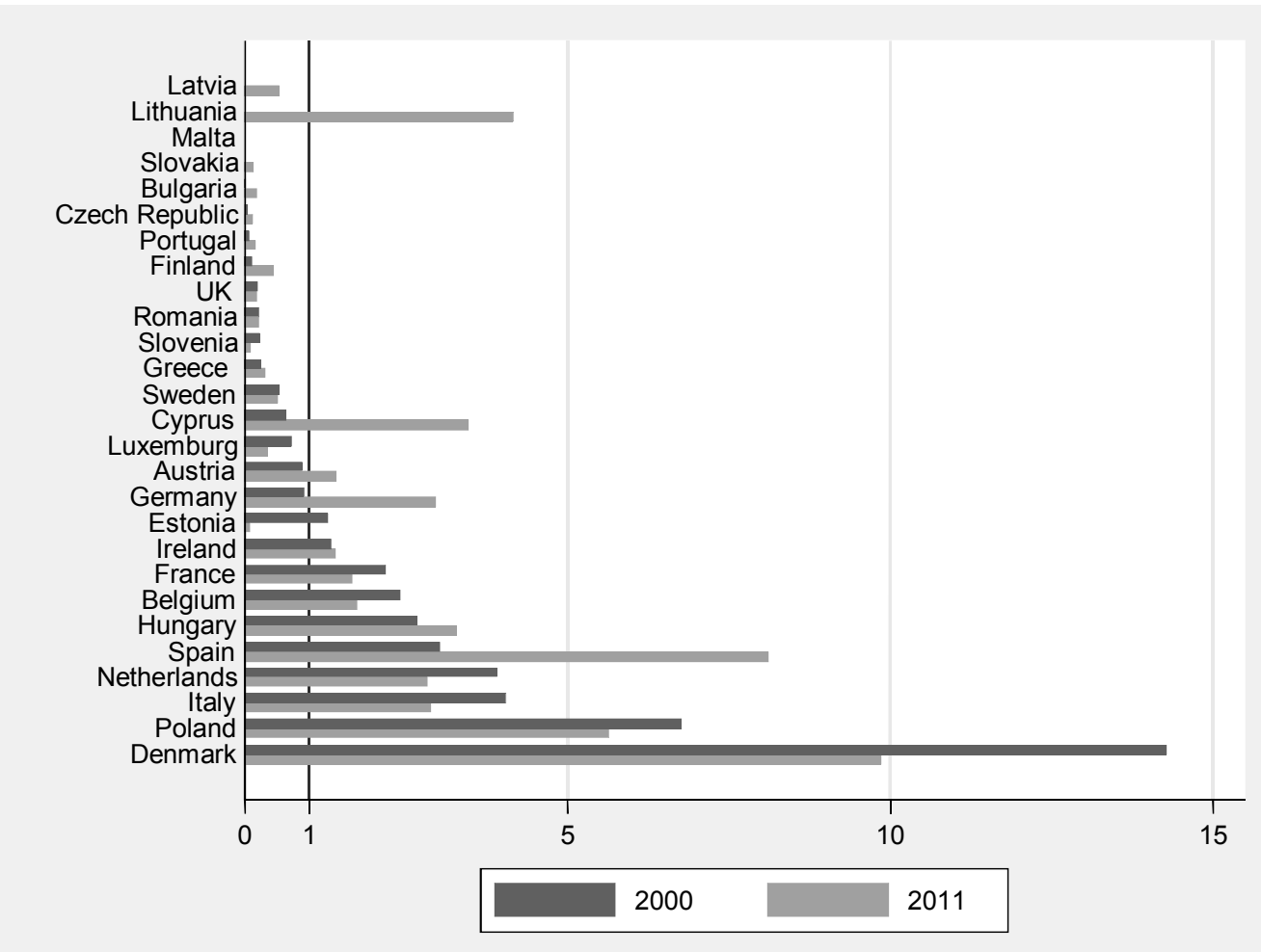

Fig. 4. Revealed comparative advantage (RCA) indices on the global market for the BEC 121 - processed meat products mainly for industry by the EU-27 member states, 2000 and 2011. Source: Own calculations based on Comtrade database with WITS (World Trade Integration Solution) software.

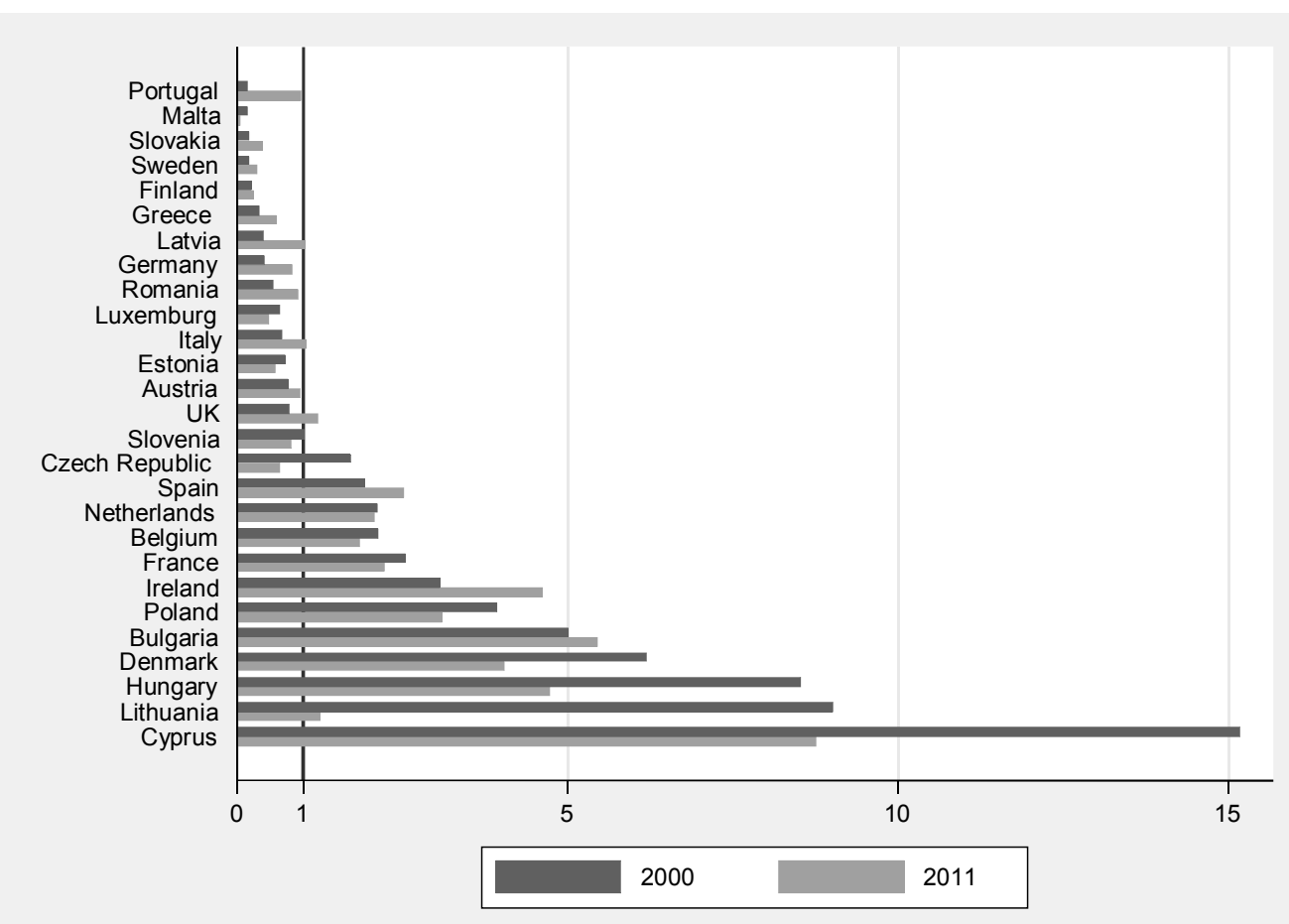

Fig. 5. Revealed comparative advantage (RCA) indices on the global market for the BEC 122 - processed meat and meat products intended for final consumption in households by the EU-27 member states, 2000 and 2011. Source: Own calculations based on Comtrade database with WITS (World Trade Integration Solution) software. 


\section{Mobility of the RCA indices}

The degree of mobility in patterns throughout the entire distribution of the RCA indices on the global market of the EU-27 member states is estimated using the mobility index, $\mathrm{M}_{1}$, based on the Markov transition probability matrices using a one-year lag. If the $\mathrm{M}_{1}$ index is low (closer to zero than two, in this case), the stability in RCA indices is high.

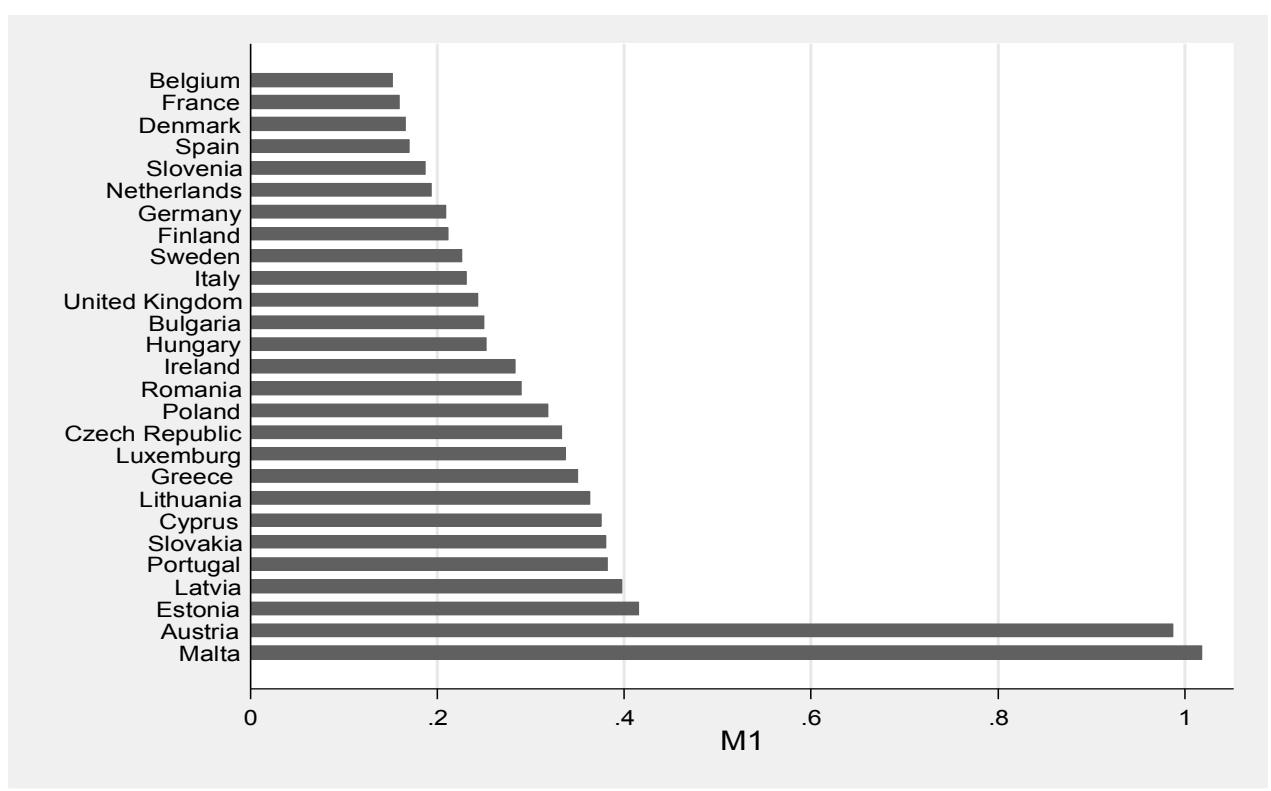

Fig. 6. Mobility of RCA Indices, 2000-2011. Note: $M_{1}$ can take values: $0<M_{1}<2$. Source: Own calculations based on Comtrade database with WITS (World Trade Integration Solution) software

The empirical results in Figure 6 indicate that, except for Malta (1.098) and Austria (0.988), the $M_{1}$ indices for meat products are relatively low, which indicates a rather high stability in the evolution of developments of the RCA indices with a relatively low degree of mobility throughout the entire distribution in patterns of the RCA indices for meat chain products.

\section{Duration Analysis of the Revealed Comparative Advantages (RCA $>1$ )}

The duration of the RCA $>1$ indices on the global market over time is investigated by the survival analysis using the nonparametric Kaplan-Meier product limit estimator. If the Kaplan-Meier survival rate is high, then the stability in the RCA>1 indices is high. Figure 7 presents the Kaplan-Meier survival rates for the duration analysis for the meat chain RCA>1 indices of the EU-27 member states for Year 12 (2011), the last analysed year.

The survival rates for the meat chain RCA $>1$ indices on the global markets declined substantially after 12 years. They are the highest for Ireland (0.2321), followed by Spain, the Netherlands, France, Poland, Belgium, Denmark, Cyprus, and Hungary (0.1174). These countries experienced longer durations of the RCA $>1$ indices, which suggests greater export competitiveness on the global meat markets. Malta (zero survival rate), Sweden, Luxembourg, Finland, the Czech Republic, Greece, Estonia and Slovakia experienced shorter durations of the RCA $>1$ indices, which suggests relatively low export competitiveness on the global meat markets. Relatively low survival rates can also be seen for the following EU-27 member states: Austria, Bulgaria, Germany, Italy, Latvia, Lithuania, Portugal, Romania, Slovenia, and the UK.

Substantial differences can be seen from the survival rates by the BEC meat chain product groups (Fig. 8). Spain experienced the highest survival rates for the RCA $>1$ for the BEC 21 and 121, Ireland for the BEC 122, and France for the BEC 22. In the case of the BEC 121, similarly high as for Spain are the survival rates for Belgium, Denmark, France, Hungary, Italy, the Netherlands, and Poland. The highest survival rates indicate the longer duration of the RCA $>1$ indices on the global meat markets. 


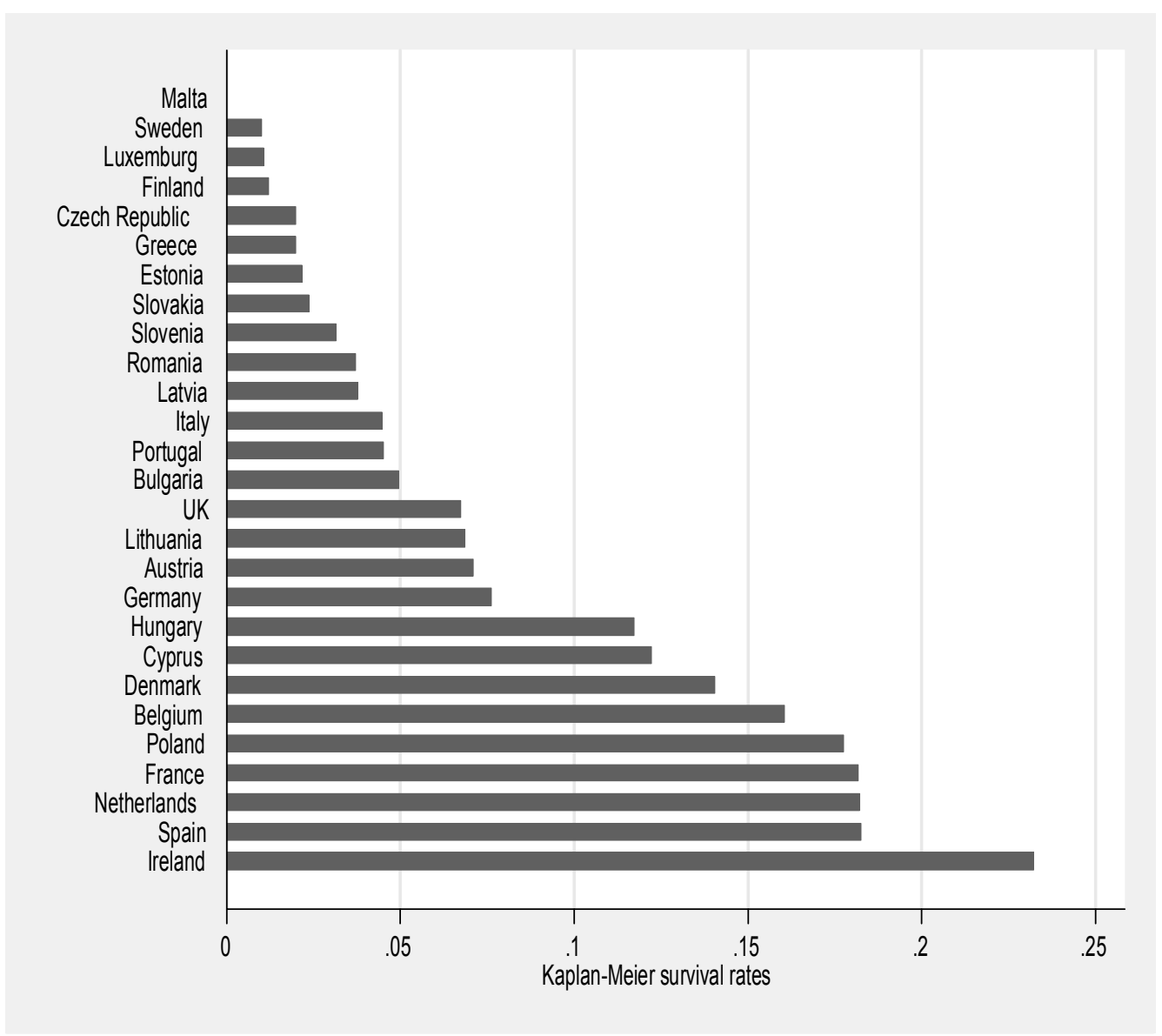

Fig. 7. Kaplan-Meier Survival Rates for revealed comparative advantage (RCA $>1$ ) indices by EU-27 member states. Source: Own calculations based on Comtrade database with WITS (World Trade Integration Solution) software

The survival rates by the BEC meat chain product groups are higher for some old EU-15 member states, e.g. for France, the Netherlands, Spain, Belgium, Denmark, and Ireland. Amongst new EU-12 member states, the survival rates are higher for Poland and to a lesser extent for Cyprus and Hungary. These higher survival rates indicate a longer duration of the RCA>1 indices on the global markets for differentiated meat chain product groups.

The case of Malta is a specific example, as none of the BEC meat chain product groups survived with the RCA $>1$ index on the global market during the 12-year period.

These export specialization patterns in differentiated meat chain products and mixed results by the EU-27 member states suggest the importance of product differentiation in vertical meat export supply chains. Meat processing can play a crucial role in meat product differentiation, meat product varieties and quality assurance in the management of meat chain supply (e.g. Barbut 2014); this can be related to innovation-creative activities towards differentiated types of meat products, which are in demand on global markets. 

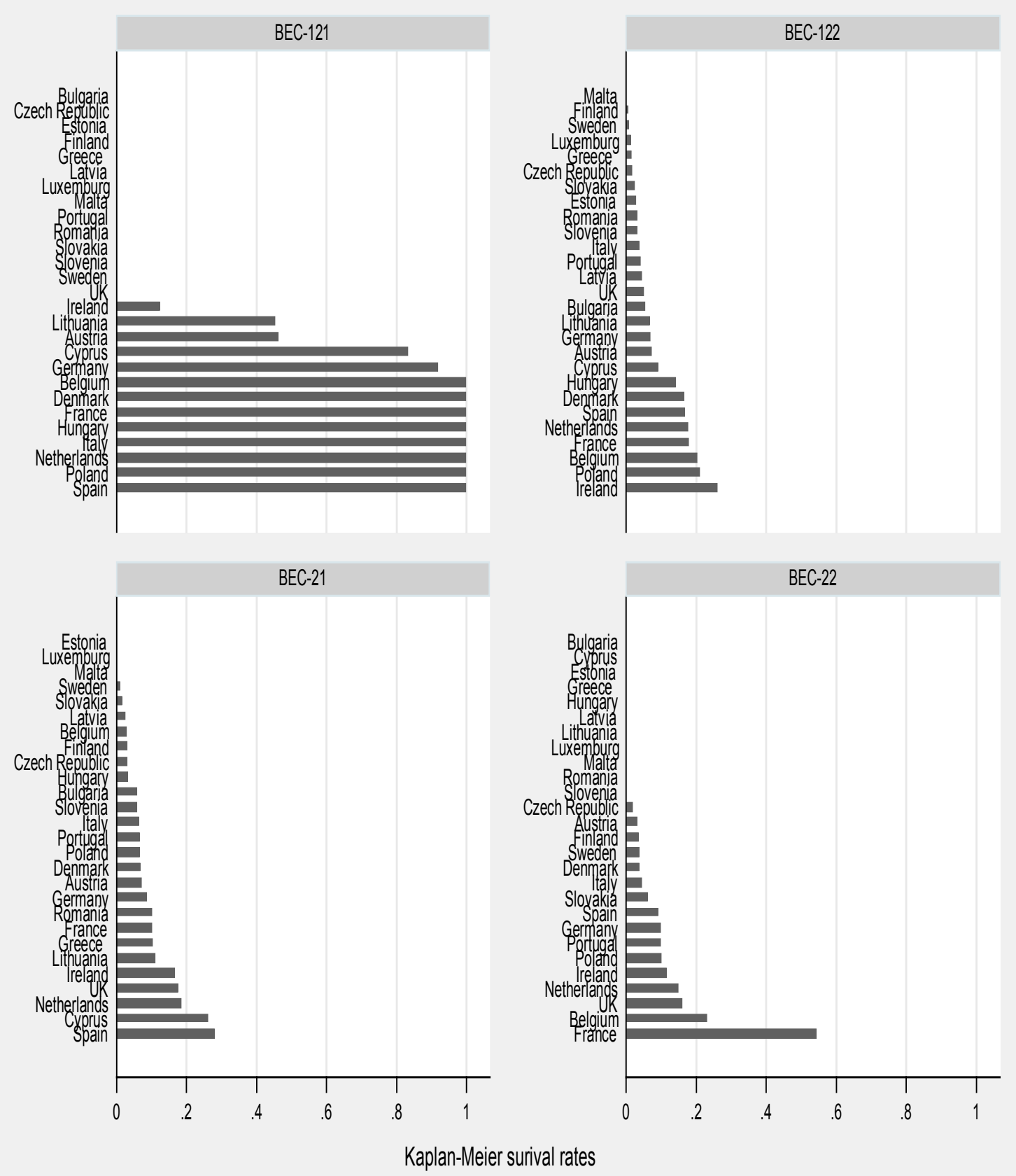

Fig. 8. Kaplan-Meier Survival Rates for revealed comparative advantage (RCA $>1)$ indices by EU-27 member states and BEC meat product groups. Source: Own calculations based on Comtrade database with WITS (World Trade Integration Solution) software

\section{Discussion}

On the basis of empirical analyses of RCA indices on global markets and the Kaplan-Maier survival rates, this paper provides insight into the level, composition and evolution in the dynamics of the RCA indices on global markets by the BEC-differentiated meat product categories. This paper contributes to the literature on meat chain competitiveness and, in particular, provides evidence for a better understanding of export competitiveness for meat chain products of the analyzed EU-27 member states. The significance of the results is for the research of meat product chain management and for policy implications.

The results on levels and evolution in patterns in the development of the RCA indices on the global meat markets are mixed within the EU-27 member states. The new EU-12 member states have largely worsened their export competitiveness on the global markets. 
Except for Malta, the survival functions differ significantly between the BEC meat chain product groups for the other EU-27 member states. Most notable is the group of the EU member states with perfect survival rates without any failure over the 12-year analysed period in maintaining the RCA $>1$ index on global markets for the BEC 121: Belgium, Denmark, France, Hungary, Italy, the Netherlands, Poland, and Spain. The perfect continued survival of the RCA $>1$ indices on the global market over the 12-year period can be explained by different factors of comparative advantages, meat quality and competitiveness, climatic and other factors of livestock production, the role of science and innovation, technological developments and structural determinants in the meat-processing sector and distribution for long-term duration in export competition (e.g. Toldrá et al. 2012). Horizontal and vertical integration of meat chain participants can be important in strengthening competitiveness across the entire meat supply chain from on-farm practices, meat science and technology, meat processing, and marketing to consumers, for a competitive meat supply chain in differentiated meat products on global markets.

The results of the EU-27 member states' meat export competitiveness can be used to derive policy implications at the micro-level for establishing a competitive meat sector. The focus should be on those meat products that are internationally competitive on a long-term basis; this is particularly relevant during the reduction or abolishment of export subsidies in the global agri-food trade. The changing global trade and marketing environment are challenging issues that can encourage entrepreneurial activities at the levels of micro-farm and firm meat processing and marketing to improve export competitiveness.

The role of public policy in the meat supply chain can be in supporting the enabling of the macro-economic and meat sector environment that considers both the supply side and the demand side on global meat markets. On the supply side, this involves strengthening global competitiveness and export specialization towards globally competitive products in the meat supply chain. On the demand side, this involves meat quality assurance at reasonable prices for segmented and differentiated meat products. Long-term sustainable meat supply chain developments require the balancing of both supply-side and demand-side forces, for which fair market competition and efficient public policy to protect consumers are rather complements than substitutes to assure the role of export competitiveness in differentiated meat products on global markets.

\section{Conclusions}

This paper provides new evidence on meat chain export competitiveness of the analysed EU-27 member states over the analysed years (2000-2011) and between the BEC meat chain product groups. It provides a picture of the EU meat export competitiveness on global markets, using the RCA index as a measure of export competitiveness. The results of the RCA index analysis and their stability using the $M_{1}$ index and the Kaplan-Meier survival rates over time provide new and original evidence of a significant scientific contribution to EU meat exports. In addition, the export competitiveness of the EU meat products is a stimulating and challenging topic for management of the meat value chain and for policy implications.

The empirical results on the levels and evolution in patterns of developments in the RCA indices on the global markets for the meat product chain have revealed two main groups of the EU-27 member states. First, there is the group of states with strong export competitiveness $(R C A>1)$ in meat products on global markets at the aggregated meat chain level and by the BEC meat groups of products. Amongst them are Belgium, Denmark, France, Ireland, the Netherlands and Spain from the old EU-15 member states, and Bulgaria, Cyprus, Hungary and Poland from the new EU-12 member states. Second, there is the group of the EU-27 member states with weak export competitiveness $(R C A<1)$ in meat products on global markets. Amongst them are Finland, Germany, Luxembourg, Portugal and Sweden from the old EU-15 member states, and Estonia, Malta, Romania and Slovenia from the new EU-12 member states. In addition, there are some EU member states that can have revealed comparative advantages (RCA $>1)$ for specialized niche meat products or only temporarily in individual years, e.g. Austria, Greece, Italy and the UK from old EU member states and Slovakia from new EU member states. Some large annual fluctuations in the RCA indices on the global market can be explained by fluctuations of meat products export values from year to year.

The heterogeneity of survival functions across the BEC meat chain product groups suggests that export specialization patterns amongst the differentiated meat groups of products differ by the EU-27 member states. This indicates that EU member states can be or cannot be competitors on global meat product chain markets, depending on the diversification segments of the meat product chain. This suggests export specialization, competitiveness and long-term survival strategy on the global meat markets towards meat product diversification via new product varieties, quality segments, brand name development, and other distribution and marketing mix activities as 
issues for future research. Distinguishing meat exports between intra-EU and extra-EU exports and intra-industry trade of intermediate EU meat products are other issues for future research. The distinction between intra-EU exports and extra-EU exports may play an important role in the context of EU accession of the new member states. Finally, export competitiveness on the global markets by some other global competitors from non-EU-27 member states is another issue for future research.

\section{Acknowledgements}

This publication was generated as part of the COMPETE Project, Grant Agreement No. 312029 (http://www. compete-project.eu/), with the financial support from the European Community under the 7th Framework Programme. The authors gratefully acknowledge the useful suggestions and comments made by the two anonymous journal reviewers.

\section{References}

Alessandrini, M., Fattouh, B. \& Scaramozzino, P. 2007. The changing pattern of foreign trade specialization in Indian manufacturing. Oxford Review of Economic Policy 23: 270-291.

Balassa B. 1965. Trade liberalization and revealed comparative advantage. Manchester School of Economic and Social Studies 33: 99-123.

Barbut S. 2014. Review: automation and meat quality-global challenges. Meat Science 96: 335-345.

Bojnec, Š. \& Fertő, I. 2012a. Complementarities of trade advantage and trade competitiveness measures. Applied Economics 44: 399-408.

Bojnec, Š. \& Fertő, I. 2012b. Does EU enlargement increase agro-food export duration? The World Economy 35: 609-631.

Bojnec, Š. \& Peter, G. 2005. Vertical market integration and competition: the meat sector in Slovenia. Agricultural and Food Science 14: 236-248.

Boyazoglu J. 1998. Livestock farming as a factor of environmental, social and economic stability with special reference to research. Livestock Production Science 57: 1-14.

Brasili, A., Epifani, P. \& Helg, R. 2000. On the dynamics of trade patterns. De Economist 148: 233-257.

Cleves, M.A., Gould, W.W. \& Gutierrez, R.G. 2004. An Introduction to Survival Analysis Using STATA. Texas: Stata Press, College Station. 308 p.

Dalum, B., Laursen, K. and Villumsen, G. 1998. Structural change in OECD export specialisation patterns: de-specialisation and 'stickiness'. International Review of Applied Economics 12: 423-443.

De Benedictis, L. \& Tamberi, M. 2004. Overall specialization empirics: techniques and applications. Open Economies Review 15 : 323-346.

FAO 2013. FAOSTAT Trade database. Rome: Food and Agriculture Organization of the United Nations. Available at the website: http://faostat.fao.org/site/342/default.aspx.

Fertö, I. \& Soós, K.A. 2008. Trade specialisation in the European Union and in European former communist countries. Eastern European Economics 46: 7-31.

Gibon, A., Sibbald, A.R., Flamant, J.C., Lhoste, P., Revilla, R., Rubino, R. \& Sørensen, J.T. 1999. Livestock farming systems research in Europe and its potential contribution for managing towards sustainability in livestock farming. Livestock Production Science 61: 121-137.

Hansson, H., Ferguson, R. \& Olofsson, C. 2010. Understanding the diversification and specialization of farm businesses. Agricultural and Food Science 19: 269-283.

Hillman A.L. 1980. Observations on the relation between 'revealed comparative advantage' and comparative advantage as indicated by pre-trade relative prices. Weltwirtschaftliches Archiv 116: 315-321.

Hinloopen, J. \& van Marrewijk, C. 2008. Empirical relevance of the Hillman condition for revealed comparative advantage: 10 stylized facts. Applied Economics 40: 2313-2328.

Lafay G. 1992. The measurement of revealed comparative advantages. In: Dagenais, M.G. and Plunet, P-A. (eds.). International Trade Modelling. London: Chapman \& Hall. p. 209-236.

Nardone, A., Ronchi, B., Lacetera, N., Ranieri, M.S. \& Bernabucci, U. 2010. Effects of climate changes on animal production and sustainability of livestock systems. Livestock Science 130: 57-69.

Quah D. 1993. Empirical cross-section dynamics in economic growth. European Economic Review 37: 426-434.

Quah D. 1997. Empirics for growth and distribution: polarization, stratification, and convergence clubs. Journal of Economic Growth 2: 27-59.

Redding S. 2002. Specialization dynamics. Journal of International Economics 58: 299-334.

Shorrocks A. 1978. The measurement of mobility. Econometrica 46: 1013-1024. 
Toldrá, F., Aristoy, M.-C., Mora, L. \& Reig, M. 2012. Innovations in value-addition of edible meat by-products. Meat Science 92 : 290-296.

United Nations Statistical Division (UNSD) 2013. Commodity Trade Database (COMTRADE), available through World Bank's World Integrated Trade Solution (WITS) software: www.wits.worldbank.org.

Van der Zijpp, A.J. 1999. Animal food production: the perspective of human consumption, production, trade and disease control. Livestock Production Science 59: 199-206.

Wever, M., Wognum, N., Trienekens, J. \& Omta, O. 2010. Alignment between chain quality management and chain governance in EU pork supply chains: a transaction-cost-economics perspective. Meat Science 84: 228-237.

Yu, R., Cai, J. \& Leung, P.S. 2009. The normalized revealed comparative advantage index. Annals of Regional Science 43: $267-282$. Zaghini, A. 2005. Evolution of Trade Patterns in the New EU Member States. Economics of Transition 13: 629-658.

Zhou, G., Zhang, W. \& Xu, X. 2012. China's meat industry revolution: challenges and opportunities for the future. Meat Science 92: 188-196. 